\title{
Sistem Pengelolaan Zakat Di Era Modern
}

\author{
Tafsiruddin \\ STAI Diniyah Pekanbaru \\ Jl. KH. Ahmad Dahlan Pekanbaru \\ tafsiruddin123@gmail.com
}

\section{Abstrak}

Zakat merupakan salah satu rukun Islam yang diwajibkan bagi setiap umat muslim, baik laki-laki atau perempuan. Kedudukan zakat sangatlah penting dalam Islam hal ini memang diprintahkan oleh alloh SWT. Perlu kita pahami bersama bahwa zakat merupakan ibadah yang tidak hanya memiliki nilai hubungan vartikal, antara manusia dengan alloh, tetapi zakat juga memiliki nilai kehidupan manusia akan menjadi harmonis, orang kaya akan memperoleh kepuasan batin karena bisa menolong sesama muslim yang kurang mampu, yang kurang mampu dapat memanfaatkan harta zakat yang diterima dari orang mampu yang telah mengeluarkan zakatnya. Dengan adanya zakat harapannya kebutuhan ummat kurang mampu dapat terpenuhi. Zakat akan berjalan dengan baik, efektif dan tepat sasaran bila harta zakat di kelola dengan menejemen yang baik, lebih-lebih pada era gejed pada saat ini, memudahkan para muzakki untuk membayarkan zakat. Sejarah telah membuktikan bahwa penerapan program zakat yang telah dilaksanakan oleh lembaga-lembaga zakat atau dilakukan oleh para sahabat Nabi memang betul-betul dapat mengentaskan kemiskinan, membantu orang yang lemah, bahkan pada masa pemerintahan Khalifah Umar bin abdul aziz sampai tidak ada yang berhak menerima zakat, karena seluruh penduduknya sudah kaya. 


\section{Abstract}

Zakat is one of the pillars of Islam that is required for every people Muslim who is able, either male or female. Position zakat is very important in Islam case is indeed order by Allah SWT, and also many hadiths prophet explained about the obligation to zakat on property objects were in had. Need we understand together that the charity is worship that not only has the value of the relationship vertical, between humans by Allah, but the charity also has the value of the lives of human beings will be harmony, the rich will gain the satisfaction of the mind because it could help fellow Muslims who may be less capable, and that less capable of (poor) to utilize the wealth of zakat are accepted from those capable of (wealthy) who have issued their zakat. With the charity hopes the needs of the ummah who are less able to be fulfilled, including among others the alleviation of poverty. Zakat will run with good, effective, and precise target when property zakat in governance with management was good as well, especially in the era $\mathrm{Hp}$ at the moment is actually also adds convenience for the Muzakki to pay zakat on property and himself. History has proved that the implementation of the program of zakat which has been implemented by the institutions of zakat or carried out by the companions of the Prophet was actually able to alleviate poverty, help the person who is weak, even at times reign of Caliph Umar bin Abdul Aziz until no there are entitled to receive zakat because the entire population is already wealthy or already be Muzakki (people who tithe).

Kata Kunci: Landasan hukum zakat, manfaat dan menejemen zakat di era modern.

Keywords: Basis law zakat, the benefits and management of zakat in the modern era. 


\section{A. Pendahuluan}

Sebelum Peneliti Menjelaskan lebih mendalam dan memaparkan hasil peneltiannya terkait dengan sistem Pengelolaan zakat di Era Modern, maka sangatlah penting untuk kita ketahui tentang pengertian zakat terlebih dahulu, kalo dilihat dari suku kata nya,Zakat berasal dari bahasa arab yaitu 'az-zakah' Ia adalah masdar dari fi'il madli 'zakka' yang berarti bertambah, tumbuh dan berkembang. Ia juga bermakna suci, definisi ini mengacu pada firman Alloh dalam al-Qurán surat as-Syams yang Artinya, sungguh beruntung orang yang menyucikan hati. ${ }^{1}$ Harta di sebut zakat, karena sisa harta yang telah di keluarkan dapat berkembang lantaran harta yang di zakati menjadi berkah berangkali berkah karena atas do'a orang-orang yang menerimanya, selain itu Juga kerena harta yang dikeluarkan adalah kotoran yang akan membersihkan harta seluruhnya dari syubhat dan mensucikannya dari hakhak orang lain di dalamnya.

Secara etimologis zakat berarti kebersihan, perkembangan dan berkah.Maksudnya adalah bersih, dan bertambah.Bisa juga di artikan dengan di berkahi. Inilah arti yang dikehendaki oleh Islam. Sebab barangsiapa yang mengeluarkan zakat berarti ia telah membersihkan dirinya dan mensucikan hartanya dari sesuatu yang kotor, sehingga bisa diharapkan bertambahnya pahala dan hartanya di berkahi. Zakat menurut definisi ulama ahli fikih, adalah menyerahkan harta yang telah ditentukan oleh syariat kepada orang-orang yang berhak menerimanya. ${ }^{2}$

Dalam jurnal ini peniliti juga akan menjelaskan terkait dengan hukum berzakat, fungsi dan menejemen pengngelolaan zakat serta peneliti memaparkan hasil penelitian terkait dengan sistem berzakat dan pengelolaan di Era Modern saat

\footnotetext{
${ }^{1}$ Al-Qurán Dan terjemah, Kemenag RI, hlm, 595.

${ }^{2}$ Wisnu Jatmiko dkk, Sistem iformasi zakat, hIm 65.
} 
ini. Peneliti berharap hasil peneltian ini bisa menjadi referensi bagi setiap pembaca, betapa mulyanya berzakat itu, betapa pentingnya zakat dikelola, dan terhusus bagi para pengelola lembaga-lembaga zakat.

\section{B. METODE PENELTIAN}

Seorang peneliti ketika melakukan sebuah penelitian maka sebelumnya harus memahami, menetapkan metode penelitan apa yang akan digunakan, agar supaya penelitiannya keredibel dan mayakinkan, kenapa demikian karena pada umumnya penelitian dilapangan setidaknya tidak akan terlapas dari sebuah pertanyaan, pengumpulan data dengan melihat dukumen dan melakukan obserfasi. Data yang dimaksud adalah semua fakta yang di temukan sebagai bahan penyusunan sebuan informasi, data yang baik akan berguna untuk mengetahui atau memperoleh gambaran secara jelas tentang suatu keadaan, untuk membuat kesimpulan atau keputusan dalam memecahkan suatu permasalahan, data yang baik sebagai dasar evaluasi apa yang telah diperoleh. ${ }^{3}$

Dalam penelitian ini peneliti menggunakan metode kualitatif, dalam penelitian kualitatif pengumpulan data dilakukan pada naturan setting. Pengumpulan data denagn cara observasi, observasi dilakukan dengan cara mengamati perilaku, kejadian, kegiatan yang dapat disaksikan baik kegiatan perorangan atau kelompok sebagaimana dalam lembaga-lembaga badan amil zakat. ${ }^{4}$ Dalam Observasi partisipatif peneliti terlibat dengan kegiatan sehari-hari orang yang sedang diamatinya, jadi observasi partisipasi merupakan metode pengumpulan data yang digunakan agar memperoleh data penelitian melalui pengamatan dan pengindraan dimana

\footnotetext{
${ }^{3}$ Maleong, Lexy J. metode penelitian kualitatif, Bandung, PT. Remaja Rosdakarya, 2010, hlm, 157

${ }^{4}$ Sugiono, metode penelitian kombinasi. Bandung, alfabeta,2013, hlm, 309
} 
observer benar-benar dalam keseharian. Objek observasi dalam peneltian kualitatif yang di observasi menuru spadley dinamakan situasi social yang terdiri atas tiga komponen yaitu, Pkace (tempat), Actor (Pelaku) dan activities (Aktifitas kegiatan $)^{5}$. Dalam penelitian yang berjudul "tentang sistem pengelolaan zakat di era modern" ini peneliti mengunakan motode pendekatan kualitatif, sehingga peneli bisa melakukan observersi pada lembaga-lembaga zakat yang ada.

\section{PEMBAHASAN}

Memahami landasan hukum zakat dalam pandangan Islam adalah suatu hal yang sangat penting, Zakat merupakan salah satu rukun Islam, yang diperintahkan Allah SWT di dalam Al-Qur'an dan juga termaktub di dalam hadist Rasulullah SAW.

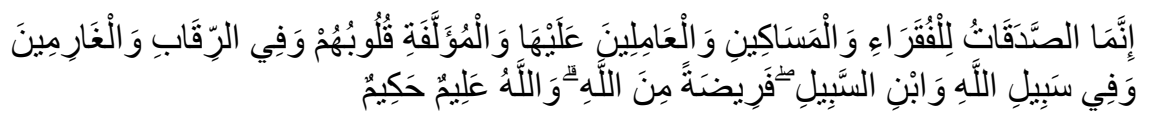

Artinya, Sesungguhnya shadaqag-shadaqah itu, hanyalah untuk orang-orang fakir, orang-orang miskin, penguruspengurus zakat, para mualaf yang di bujuk hatinya, untuk (memerdekakan) budak, orang-orang yang berhutang, untuk jalan Allah dan untuk mereka yang sedang dalam perjalanan, sebagai suatu ketetapan yang di wajibkan Allah. Dan Allah mengetahui lahi Maha Bijaksana.(Qs At-Taubah, 60). ${ }^{6}$

Ayat diatas memberikan penjelasan secara kongkrit bahwa ada manusia yang diwajibkan untuk membayar zakat, ada golongan manusia yang berhak untuk menerima zakat, manusia yang berhak menerima zakat setidaknya ada 8 golongan, pertama orang Faqir, yaitu orang tidak memiliki harta bendan yang bisa digunakan untuk kebutuhan pokok seperti makan dan minum, kedua Miskin, yaitu orang yang

\footnotetext{
${ }^{5}$ Sugiono, metode penelitian kombinasi. Bandung, alfabeta,2013, hlm, 313 ${ }^{6}$ Al-Qurán Dan terjemah, Kemenag RI, 196.
} 
tidak memiliki harta benda yang bisa mencukupi kebutuhan hidup yang diperlukannya bagi dirinya dan keluarga yang wajib ditanggung nafkahnya, ketiga orang yang bersetatus Amil, yaitu orang yang mengumpulkan, membagikan dan mencatat harta zakat, empat Muálaf, yaitu orang baru masuk islam (orang Mu'alaf ini menurut imam Syafi'I ada yang boleh menerima zakat dan ada yang tidak), kelima Riqab, yaitu hamba sahaya (Pudak), enam Ghorim, yaitu orang yang memiliki tanggungan hutang naming hutangnya tidak untuk keperluan maksiat kepada alloh, tujuh Sabilillah, dan delapan Ibnu Sabil yaitu orang yang sedang dalam bepergian jauh. ${ }^{7}$

Adapun mengenai dasar hukum, banyak termaktub di dalam Al-Qur'an dan hadist Nabi. Dalam al-Qurán Allah SWT berfirman:

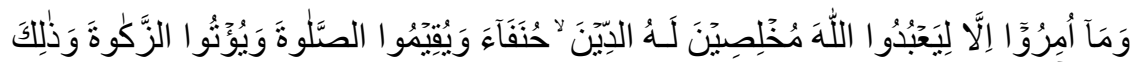

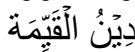

Artinya, Padahal mereka tidak disuruh kecuali supaya menyembah Allah dengan memurnikan ketaatan kepada-Nya dalam (menjalankan) agama yang lurus, dan supaya mereka mendirikan shalat dan menunaikan zakat; dan yang demikian itulah agama yang lurus. (QS, Al-Bayyinah, 5).8

Dalam ayat lain alloh berfirman:

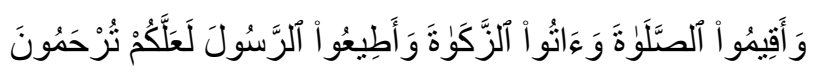

Artinya, Dan dirikanlah sholat, tunaikanlah zakat dan taatlah kepada Rasul, supaya kamu diberi rahmat, (QS. AnNur,Ayat 56)

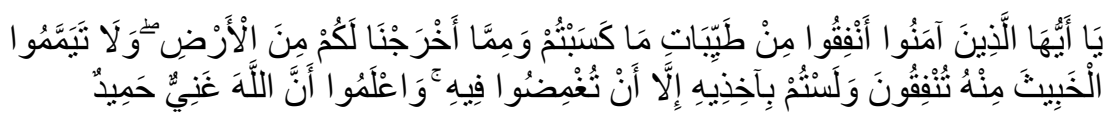

\footnotetext{
7 Jalaluddin As-Suyuti, Tafsir jalalain, hlm, 143.

${ }^{8}$ Al-Qurán Dan terjemah, Kemenag RI, 598.
} 
Artinya, Hai orang-orang yang beriman, nafkahkanlah ( di jalan Allah) sebagian dari hasil usahamu yang baik-baik dan sebagian dari apa yang kami keluarkan dari bumi untukmu. Dan janganlah kamu memilih yang buruk-buruk lalu kamu menafkahkan daripadanya, padahal kamu sendiri tidak mau mengambilnya melainkan dengan memicingkan mata terhadapnya. Dan ketahuilah, bahwa Allah Maha Kaya lagi Maha Terpuji, (QS. Al-Baqarah, Ayat 267)

Selain ayat-ayat Al-Qur'an di atas, ada sebuah hadist Rasulullah SAW yang mewajibkan tentang zakat fitrah dari ibnu Umar RA, yang artinya, Sesungguhnya Rasulullah S.A.W. telah mewajibkan zakat fitrah pada bulan Ramadhan satu sha' kurma atau satu sha' gandum kepada setiap orang yang merdeka, hamba sahaya, laki-laki maupun perempuan dari kaum Muslimin.

Sebagai umat Islam hendaknya kita dapat memahami harta-harta yang harus di zakati, agar kita mudah dalam melaksanakan salah satu rukun Islam berupa kewajiban berzakat, berikut ini peneliti jelaskan tentang macam-macam harta yang harus di zakat:

1. Zakat perdagangan

Setiap harta benda kekayaan yang dihasilkan dari jual beli atau perniagaan, maka disebut harta dagangan, harta dangan bila sudah mencapai nisab dan memenuhi persyaratan maka wajib di kelurkan zakatnya, harta dagangan apapun bentuknya wajib untuk dizakati, walaupun awalnya harta tersebut tidak wajib untuk di zakati seperti pakaian, pakaian menjadi wajib untuk dizakati bila diperjual belikan, jumlah nilai harta dagangan tersebut sudah dikurangi kewajiban untuk melunasi hutang, jika hutang tersebut ada. Harta dagangan memiliki nisab setara dengan nilai emas 85 gram dan telah berusia setahun (masa haul), besaran zakat yang harus dibayarkan adalah 2,5\% dari kesuluran 
harta dagangan disaat mencapai haul. Harta dagangan yang di maksud adalah setiap harta yang diperjual belikan, bisa berupa mobil, pakain, sembako ataupun yang lainnya, termasuk uang ataupun modal yang dibutarputar dalam peruses perdagangan juga wajib di zakati.

2. Zakathasil pertanian

Apabila seseorang yang memiliki pekerjaan yang dihasilkan dari pertanian berupa makanan pokok seperti padi, gandum, jagung, maka hasil pertanian tersebut wajib untuk dizakati. Sedengkan ketentuannya sebagai berikut:

a. Mencapai nisab, yaitu, $653 \mathrm{Kg}$ Padi

b. Besaran zakat yang wajib dikeluarkan $5 \%$, bila dalam proses pengairan atas tanaman mengunakan mesin.

c. Besaran zakat yang wajib dikeluarkan $10 \%$, bila proses pengairan pada tanaman menggunakan air hujan.

d. Zakat wajib dibayarkan setiap masa panen bila mencapai satu nisab atau lebih.

3. Zakat hewan ternak

Dalam lingkungan kita kadangkala banyak kaum muslimin yang memelihara hayawan ternak seperti sapi, kerbau, kambing, atau unta sebagaimana di tanah arab, hewanhewan ternak tersebut semua wajib untuk di zakati dengan ketentuan memenuhi jumlah nisab, ketentuan nisabnya berbeda-beda diantara hayawan ternak tersebut, hayawan ternak berupa SAPI nisabnya bila sudah mencapai 30 ekor. Hayawan ternak berupa KAMBING jumlah nisabya 40 ekor. Hayawan ternak UNTA jumlah nisabnya 5 ekor, dari hayawan yang sudah mencapai nisab tersebut juga harus sudah memenuhi masa haul. ${ }^{9}$

4. Zakat emas dan perak

\footnotetext{
${ }^{9}$ Ibrahim al-Bajuri, al-Bajuri Ibnu Qasim, hlm, 269
} 
Kaum meslimin yang memiliki harta benda simpanan berupa emas dan perak, maka ia wajib untuk membayar zakatnya dengan ketentuan emas atau perak sudah mencapai masa haul (satu tahun), mencapai nisab dengan berat 85 gram emas murni. Adapun besaran zakatnya 2,5 persen dari emas murni tersebut.

Berikutnya yang harus kita pahami bagaimana cara menghitung emas yang wajib di zakati, pertama jika seluruh emas yang dimiliki tidak dipakai untuk berhias atau dipakai hanya setahun sekali, kedua zakat emas yang dimiliki dihitung nilai harganya dikalikan 2,5 persen, ketiga jumlah nilai dari nisab 2,5 persen dikurangi dengan nilai emas yang dipakai berhiyas sehari-hari jika emasnya ada yang dipakai berhiyas dan ada yang disimpan.

Cara menghitung zakatnya perak dengan ketentuan sebagai berikut, pertama seluruh perak yang di miliki tidak digunakan untuk berhiyas seharai-hari atau berhiyas setahun sekali, kedua zakat yang harus dikuluarkan 2,5 persen dari jumlah perak yang disimpan, ketiga bila peraknya ada yg dipakai berhiyas dan ada yang tidak dipakai berhiyas, maka zakatnya 2,5 persen dikurangi dari jumlah emas yang dipakai untuk berhiyas.

5. Zakat profesi

Yang di maksud zakat profesi ialah zakat yang dikularkan dari pendapatan hasil kerja seseoraang atau dinamakan zakat penghasilan, dan harus mengeluarkan zakatnya apabila pendapatan tersebut sudah mencapai satu nisab, jumlah zakatnya setara dengan beras sebanyak $520 \mathrm{Kg}$ beras, dan zakat yang harus dikeluarkan 2,5\%.

6. Zakat investasi

Zakat investasi ini merupakan harta zakat seseorang, dimana orang tersebut memiliki investasi atas harta benda yang mereka miliki, semesal kendaraan yang disewakan. Zakat investasi dikeluarkan pada saat 
mendapatkan penghasilan dan modal investasi tidak dikenai kewajiban zakat, dan zakat yang harus dikeluarkan sebesar 5\% dari total keuntungan investasi.

7. Zakat tabungan

Bagi seorang muslim yang memiliki uang dan disimpan selama satu tahun, dan nilai uang tersebut sudah setara dengan Emas 85 gr, maka ia wajib mengeluarkan zakatnya sebesar 2,5\%.

8. Zakar Harta rikaz

Apabila ada harta tamuan dari harta benda yang terpendam dalam tanah selama bertahun-tahun atau harta Rikaznya berupa emas, perak yang tidak diketahui lagi siapa pemiliknya, maka wajib dikeluarkan zakatnya sebesar $20 \% .^{10}$

9. Zakat Fitrah

Selain model-model zakat yang telah disebutkan diatas, dalam islam juga ada yang namanya zakat fitrah, dan zakat fitrah ini diwajibkan bagi setiap orang muslim baik yang masih keadaan banyi, anak2, remaja bahkan dewasa semua wajib untuk berzakat bila ia menjumpai sebagain bulan suci ramadhan dan sebagian bulan syawal, maka dengan demikian dapat dipahami bila ada anak yang lahir pada malam tanggal satu bulan syawal maka ia tidak wajib dizakati, begitu juga bila ada orang meninggal dunia pada akhir bulan suci ramadhan maka ia juga tidak wajib untuk dizakati. Ukuran zakat fitrah yang harus dikeluarkan bagi setiap orang muslim sebesar $2,7 \mathrm{~kg}$ menurut pendapat iamam Syafi'i.11

Dalam penjelasan lain Zakat Fitrah yaitu, zakat badaniyah manusia itu sendiri, artinya setiap orang yang beragama

\footnotetext{
${ }^{10}$ H.M Aryad Thali, Ilmu Fikih, Medan Pustaka Muzir, 1982, hlm, 69.

${ }^{11}$ Tafsir, Statmen puasa akumulasi fikh dan hadis, BEM F-IAIT, Kediri,2017, hlm 38.
} 
islam bila di menemui bulan suci Ramadan dan juga menemu bulan syawal, maka ia diwajibkan untuk membayar zakat fitarah, baik ia sudah dewasa atau belum, seperti anak-anak juga wajib membayar zakat fitrah, tentu yang membayarkan zakatnya adalah orang tuanya. Dan harta yang digunakan untuk membayar zakat fitrah adalah makanan sehari-hari, seperti kurma, gandum dan baras. Kewajiban zakat fitrah ini memang berdasarkan hadis Nabi Muhammad saw yang artinya, Dari ibnu umar ra, bahwa Nabi mewajibkan zakat fitrah, satu sho' kurma, gandum, bagi hamba, orang merdeka, laki-laki, perempuan, anak kecil dan orang dewasa, yang mana mereka itu beragama islam, dan Nabi memerintahkan membayar zakat sebelum manusia keluar untuk melakukan shalat idul fitri. ${ }^{12}$

Agar supaya termotifasi dalam berzakat hendaknya kita mengetahui manfaat dan hikmah dabalik harta zakat. Kalo kita mau memmahami dengan baik zakat merupakan ibadah yang mengandung dua dimensi, pertama, dimensi hubungan manusia dengan alloh (hablum minaalloh), kedua, hubungan seorang manusia dengan manusia lainnya (hablum minannas), dalam berzakat memiliki bebberapa tujuan dan manfaat yang hendak dicapai oleh manusia dan ajaran sariat islam yang telah mewajibkannya atas ibadah zakat tersesbut, diantara tujuan dan manfaatnya adalah:

1. Zakat dapat mengangkat derajat orang fakir miskin, karena dengan harta zakat itu kesulitan ekonomi dan penderitaan hidup akan terbahtu.

2. Harta zakat akan dapat dapat memberikan solusi permasalahan yang dihadapi oleh para orang yang berhak menerima zakat, dalam al-Qurán disebut Mustahiq.

12 Ibnu Hajar al-Asqolani, Buluhul Marom, hlm, 131. 
3. Zakat dapat membentenge dan mempererat tali persaudaraan sesame umat islam, bahkan manusia pada umumnya.

4. Zakat dapat menghilangkan sifat kikir yang ada pada manusia atas harta kekayaan yang dimiliki.

5. Zakat dapat membersihkan sifat-sifat dengki iri hati, bahkan dapat menghilangkan kesenjangan social diantara manusia, yaitu, orang yang mampu dengan orang yang tidak mampu.

6. Zikat bisa menjembatani jurang pemisah diantara orang yang kaya dengan orang miskin.

7. Zakat dapat menumbuhkan rasa tangung jawab sosial yang tingi pagi manusia yang rajin membayarnya.

8. Sebenarnya zakat juga akan mendidik manusia untuk menjadi disiplin dalam menunaikan kewajiban dan memberikan hak-hak orang lain.

9. Zakat juga menjadi sarana untuk mewujudkan keadilan social di tengah-tengah masyarakat.

Adapunzakat memiliki hikmah-hikmah sebagai berikut:

a. Zakat dapat memelihara dan menjaga harta benda dari incaran orang-orang yang tidak bertanggung jawab, yaitu pelaku dosa dan pencuri.

b. Zakat merupakan merupakan pertolongan bagi orangorang sangat membutuhkan bantuan materi dan bisa mendorong semangat bekerja bagi manusia, ketika mereka mampu melakukannya, maka ia akan mudah dapat mewujudkan kehidupan yang lebih baik.

c. Zakat sebenarnya dapat melitih bagi manusia untuk menjadi orang yang dermawan (suka member orang lain). 
d. Zakat diwajibkan juga merupakan bentuk syukur seorang hamba atas nikmat-nikmat yang telah alloh berikan kepada mereka. ${ }^{13}$

Di era yang serba teknologi, serba online, sebenarnya memudahkan kaum muslimin dialam menggelola harta zakat, menejemen pengelolaan yang ditunjang dengan alat kompiuter yang canggih, namun kita juga harus memahami tentang menejemen itu sendidri, secara harfiah menejemen berasal dari bahasa enggris 'management' yang memiliki arti mengemudikan, mengurus, mengatur dan dapat juga diartikan pengngelolaan, dengan demikian manajemen secara hakiki adalah bagaimana orang yang terlibat di dalam sebuah organisasi itu mampu mengelelola harta zakat atau mengurus harta zakat yang di terima oleh para muzakki dengan baik, sehingga tercapailah tujuan lembaga zakat tersebut dengan baik pula. Pernyataan ini telah didukung oleh Everard dan Morris yang menyatakan bahwa manajemen adalah merupakan kegiatan untuk "menyusun arah, tujuan dan sasaran". Secara istilah, Ir. Tom Degenaars, tersebut dalam "System Analyses and Quantitative technique bahwa ia menyatakan "Manajement is defined as a process dealing with a guided group activity and based on distinct objectives which have to be achieved by the involment of human and non human resousces. ${ }^{14}$

Dalam penjelasan lainManajemen adalah suatu proses yang berhubungan dengan bimbingan kegiatan kelompok berdasarkan atas tujuan yang jelas yang harus dicapai dengan memperdayakaan sumber-sumber SDM yang di miliki manusia. Sementara itu George $\mathrm{R}$ Terry menyatakan bahwa "management is a distinct process consisting of planing, organizing, actuating and controlling, utiliting in each both

\footnotetext{
${ }^{13}$ Fikih siswa, kementrian agama RI, 2014, hlm, 40.

${ }^{14}$ Mulkanasir, Mewujudkan Manajemen Zakat yang Modern dan

Profesional.(Vol.2 No. 1 Juni 2013)
} 
scince and art, and followed in order to accomplish predetermined objektives." Manejemen adalah suatu proses yang membedakan antara perencanaan, pengorganisasian, penggerakan, pelaksanaan dan pengawasan dengan memanfaatkan ilmu dan seni agar tujuan yang telah ditetapkan dapat diselesaiakan.

Adapun zakat secara etimologi berasal dari bahasa arab : zaka-yazkuu-zakaa an (tumbuh, suci, baik, bertambah), adapun zakaatun (zakat), sedekah, kebersihan. Dalam kitab-kitab hukum Islam, perkataan zakat itu diartikan dengan suci,tumbuh dan berkembang serta berkah. Dan jika pengertian itu dihubungkan dengan harta, maka menurut ajaran Islam, harta yang dizakati itu akan tumbuh berkembang, bertambah karena suci dan berkah, bisa membawa kebaikan bagi hidup dan kehidupan yang punya. Maka,zakat adalah bagian dari harta yang wajib diberikan oleh setiap muslim yang memenuhi syarat kepada orang-orang tertentu, dengan syarat-syarat tertentu pula. Dan zakat akan lebih efektif dan tepat sasaran bila zakat tersebut di kelola oleh lembaga-lembaga zakat, semisal lembaga zakat LAZIZNU dan BAZNAS.

Sedangkan Modern kata untuk mensifati terhadap sesutu aktifitas, kelompok, mupun bendamisalnya masyarakat modern, berfikir modern, lingkungan modern dan seterusnya. Jika dikatakan masyarakat modern maksudnya adalah masyarakat yang kondisi terakhir sudah sangat maju baik cara hidup, cara berfikir, cara penggunaan teknoligi terkini dan sebagainya.Modern berasal dari bahasa inggris dengan kata "Modern" artinya model baru. Kita semua memahami hari ini semua serba gejet, serba internet, serba online, dan ini memberikan dampak positif bagi penggunanya, karena memang dapat meminimilsir bahkan meringankan tenaga dan efesiensi waktu terkuras.

Proses transformasi antara kehidupan yang tradisional menuju kondisi kemajuan terkini dengan ciri-ciri seperti 
bagimana cara berfikir, cara bertindak danseterusnya inilah yang dusebut dengan modernisasi. Soerjono Soekanto mengemukakan sebagaimana dikutip dalam salah satu situs internet bahwa sebuah modernisasi memiliki syarat-syarat tertentu, yaitu sebagai berikut:

1. Cara berpikir yang ilmiah yang berlembaga dalam kelas penguasa ataupunmasyarakat.

2. Sistem administrasi yang baik, yang benar-benar mewujudkan birokrasi.

3. Adanya sistem pengumpulan data yang baik dan teratur yang terpusat pada suatu lembaga atau badan tertentu.

4. Penciptaan iklim yang menyenangkan dan masyarakat terhadap modernisasi dengan cara penggunaan alatalat komunikasi massa.

5. Tingkat organisasi yang tinggi yang di satu pihak berarti disiplin, sedangkan

di lain pihak berarti pengurangan.

Sudah saatnya pengelolaan zakat beralih dari model yang tradisionalkonvensional ke modern dan profesional. Dalam hal ini, model pengelolaan tradisionalkonvensional adalah pengelolaan yang dilakukan sambil lalu atau sekadarnya saja, temporer (pendek terbatas), dan dikelola oleh orang-orang yang kurang kompeten. Pengelolaan zakat yang sekadar berbekal semangat seadanya ini sudah seharusnya diubah menjadi model pengelolaan zakat yang berkualitas, modernprofesional.

Untuk mewujudkan model pengelolaan zakat yang modern dan profesional diperlukan adanya upaya yang dilakukan secara konsisten baik yang berkaitan dengan prinsip-prinsip, visi, misi dan tujuan, perencanaan, model perekrutan, maupun transfaransi pengelolaan keuangan, lalu perlu pula memadukan manajemen modern dengan spiritual manajemen agar menghasilkan hasil yang luar biasa. 
Model pengelolaan zakat yang modern dan profesional memiliki beberapa ciri utama sebagai berikut:

1. Pengelolaan zakat secara full time,yaitu pengelolaan zakat yang dilakukan dalamjam kerja sehari sekitar 8 jam dengan jumlah hari kerja minimal lima hari dalamseminggu.

2. Harta zakat dikelola oleh orang-orang ayng memiliki kompetensi, yaitu setiap tenaga 9amil Zakat) memiliki kapasitas dan kapabilitas sesuai dengan pos kerjanya masing-masing.

3. Seluruh pengelola (amil zakatnya) mendapatkan balasan jasa yang wajar, yatu, eluruh pengelola ayng terlibat dalam pengelolaan harta zakat tersebut mendapatkan gaji atau upah yang layak, sekurangkurangnyya memenuhi keperluan standar untuk hidup dan menghidupi keluarga tentunya dengan mengunakan standar sesuai peraturan daerahnya.

4. Orentasi penilaian di dalam lembaga zakat pada orentasi perestasi, yaitu setiap orang yang terlibat didalam pengeleloaan zakat tersebut berorentasi pada perestasi, lembaga juga menilai setiap orang dengan konribusi yang diberikan dalam pencapaian perestasi lembaga, namun bila ada orang yang tidak memiliki kemampuan sehingga tidak bisa memberikan sumbangsih pada pengelolaan lembaga hendaknya dihindari.

5. Setelah mengggunakan atau melakukan cara-cara sesuai dengan setandar menejemen modern, mekanisme yang dijalankan oleh lembaga zakat tersebut telah memenuhi standar menejemen modern, seperti nya visi misi, perencanaan tahunan, penyusunan personel, penyusunan anggaran, dan melakukan evaluasi sesuai dengan perkembangan. 
6. Lembaga telah melakukan implementasi, yaitu telah melakukan pencatatan setiap aktifitas kegiatan dalam kegiatan rutin maupun tidak, pencatatan telah dilakukan dengan standar menejemen yang bena, menyusun laporan dan berukut mempublikasikan laporan kegiatan dan keuangan pada public, sehingga masyarakat mempunyai kesepatan mengakses informasi kegiatan lembaga dengan baik, sehinggga mereka memberikan aprisiasi pada lembaga zakat tersebut.

7. Kantor yang dimilki oleh lembaga-lembaga zakat sudah sangat repsentatif untuk mengikuti kemajuan zaman, didalamnya sudah memiliki fasilitas yang komplit, computer, akses jaringan internet sudah disediakan, bahkan sistem untuk memberikan informasi siapa yang berhak menerima zakat secara tunai juga sudah di sediakan.

8. Dimasa Pandemi Cocid 19 ini lembaga-lembag zakat juga menjadi tulang punggung untuk memenuhi kebutuhuan pangan pada masyarakat, dimana mereka harus Lokdwon dan pemerintan mengajurkan tetap dirumah aja, hal ini tentunya akan berdampak pada ekonomi masyarakat yang memperhatinkan. ${ }^{15}$

\section{F. KESIMPULAN}

Zakat merupakan kewajiban bagi setiap kaum muslimin yang memang oleh Alloh diberi kelebihan rizki.Harta yang dizakai akan menjadi harta yang barokah, harta yang bermanfaat, harta yang akan menolong di akhirata pada muzakki nya.Zakat akan dapat mensucikan hati, menghilang sifat-sifat yang tidak baik kadangkala melekat pada diri

${ }^{15}$ Tafsiruddin, Observasi pada lembaga zakat, 27 April 2020. 
manusia, seperti sifat bahil, rakus, tamak dan tidak memiliki sifat belaskasihan pada orang lain, bila manusia senantiasa rajin berzakat maka sifat-sifat manusiawi yang tidak baik akan hilang.

Harta zakat sangatlah memberikan pertolongan pada orang yang berhak menerimanya, dimana mereka memang betul-betul kesulitan ekonomi sehingga terkait dengan kebutuhan hidupnya berupa sandang dan angan dapat terpenuhi.Harta zakat harus di kelola dengan baik oleh badan amil zakat dengan mengikuti standar menejemen yang di miliki, sehinga harta zakat betul-betul dapat disalurkan sesuai dengan printah al-qurán.

Tenaga menejemen yang mengelola pada badan amil zakat harus mempertimbangkan SDM manusianya, agar kedepan lembaga zakat tatap efektif didalam pengelolaannnya sehingga menjadi lebih maju dan dipercayai oleh masyarkat.Di masa pandemi Covid 19 saat ini harta zakat memang betulbetul meringankan beban hidup manusia dimana lembaga zakat secara nyata telah memberikan bantuan keterpurukan ekonomi umat.

\section{G. REFERENSI}

Al-Qurán Dan terjemah, Kemenag RI, PT. Sygma Examedia Arkaleema, 2009.

Fikih siswa, Kementrian Agama RI, 2006.

H.M Aryad Thali, Ilmu Fikih, Medan Pustaka Muzir. 2012.

Ibnu Hajar al-Asqolani, Buluhul Marom, toha putar, Semarang, 1999.

Imam As-Suyuti, Tafsir jalalain. 2002.

Ibrahim al-Bajuri, al-Bajuri Ibnu Qasim, 2001.

Maleong, Lexy J. metode penelitian kualitatif, Bandung, PT. Remaja Rosdakarya, 2010. 
J-Al-Mutharahah : Vol. 17 No. 1Januari-Juni 2020

Mulkanasir, Mewujudkan Manajemen Zakat yang Modern dan Profesiona,2013.

Sugiono, metode penelitian kombinasi. Bandung, alfabeta, 2013.

Tafsir, Statmen puasa akumulasi fikh dan hadis, BEM F-IAIT, Kediri, 2017.

Wisnu Jatmiko dkk, Sistem Iinformasi Zakat, 2017. , Sistem Informasi zakat, 2011. 